\title{
LOS AlañS
}

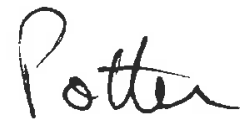

Los Alamos National Laboratory Los Alamos, New Mexico 87545

\section{memorandum}

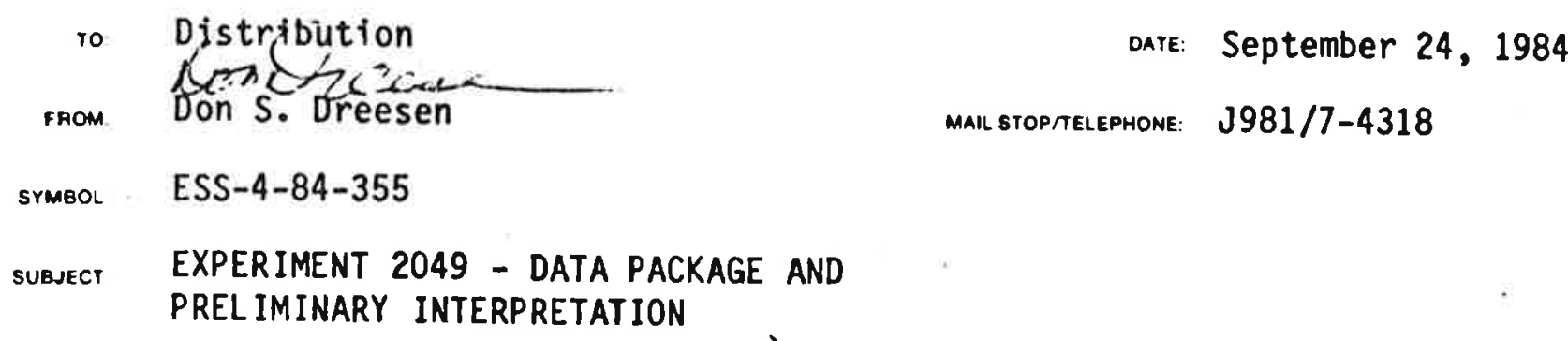

Experimental Procedure

A 2-1/8 inch OD $\times 16$ foot long (slimhole) temperature collar locator tool with the temperature probe on bottom and the collar locator 1-1/2 foot above the probe was run down the 5-1/2 inch tubing in EE-2. Temperature and casing collars were recorded. Turnaround measurements were made (shown in Table I) and no excessive cable drag was observed.

The-OTIS stinger was easily observed on the collar locator plot at 11,290 - 11,348 feet. Because the OTIS packer was set at 11,348 feet (ESS-6 wireline depth) there was concern that the stinger was sitting on top of the packer. After several, test runs of the sonde out the bottom of the stinger keeping the cable head in the stinger, it was concluded that the packer was not below the stinger. The tool was parked at 11,250 feet and water was pumped down the 5-1/2 inch tubing at $70 \mathrm{gpm}$. After 12 minutes the tool was lowered into the 9-5/8 inch casing below the OTIS stinger. Turnaround did not increase in the casing but the casing collars were off depth.

A field correlation was made using the smallest correction (-13 feet). Based on this correlation it apepared that the OTIS stinger was approximately 50 feet higher than it was originally landed and the packer was not where it had been set at 11,348 feet on the 11/27/83 $\mathrm{log}$. The maximum depth logged was 11,593 feet which was about 10 feet above the shoe base on the field correlation.

A temperature $\log$ was made from 11,593 feet to the surface with $70 \mathrm{gpm}$ flow down the 5-1/2 inch tubing (see temperature logs). Casing collars were recorded up to the top of the OTIS stinger. There was no difficulty pulling into the stinger (no indication on the wireline weight record). 


\section{Best Correlation}

The field correlation was not real good. A 46 foot joint was observed where a 38 foot joint should have been. The time drive collar logs were plotted on a commercial 20 foot per inch scale tracing paper. A better correlation was made using a +32 feet correlation to the 11/27/83 log (considering that the $11 / 27 / 83 \log$ was zeroed on the rig floor and the $9 / 28 / 84 \log$ was zeroed on the master valve, the correction was about +16 feet with an additional +16 feet for the different zerol. This correlation did not appear to be very good during the operation but the tracing paper shows it to be much better (see attached plot). Conclusions Based on Best Correlation

1. The OTIS stinger is approximately 12 feet above its original landed position.

- 2. The OTIS packer is not in its original set depth.

3. The OTIS packer is very likely 140 feet below the stinger on the obstruction observed at 11,527 (ESS-6 log 11/27/83 depth during 9-5/8 inch casing scraper run.

4. The sonde set down in the open hole about 23 feet below the 9-5/8 inch shoe.

\section{Other Observations}

1. A $16^{\circ} \mathrm{C}$ cooldown occurred with the $70 \mathrm{gpm}$ injection. Comparing depth of the stinger and 9-5/8 inch casing collars early in the cooldown with depths of the stinger and casing collars on the last run up the hole a 1.5 foot movement of the stinger (shortening of the 5-1/2 inch tubing) is observed. This may indicate the bottom 7500 feet of the 5-1/2 inch tubing is free.

2. The temperature $\log$ shows no evidence of fluid turnaround at 10,900 feet, at the bottom of the OTIS stinger or at the bottom of the $9-5 / 8$ inch casing.

3. Fluid circulation up to Madera at 2,200 feet is also indicated on the temeprature log.

A more thorough analysis of the temperature $\log$ will be made by Zora Dash and George Zyvoloski. 


\section{TABLE I}

Turnaround Measurements

Depth of Measurement

Location

$\bar{\Delta} L(f t)$

$\Delta F\left(1 b_{f}\right)$

4.000

5-1/2 in. tubing

0

75

6,039

*

1

135

8,000

n

10,000

"

10,800

"

11,000

$\omega$

1

150

11,100

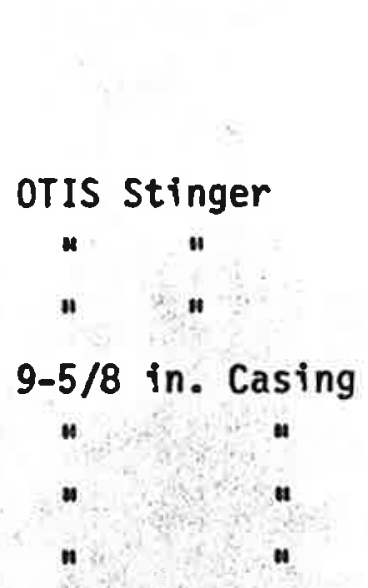

2

400

350

11,200

11,300 .

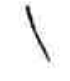

11,320

11,348

11,352

11,425

11,500

11,600

n

3

3

3

550

550

600

550

600

600

650

700

625 


\section{TABLE II}

Depth of OTIS Stinger Relative To 9-5/8 Inch Casing

Depths on 1st Run Out (Before Cooldown)

Top of Stinger 11,294

$\int \begin{aligned} & 11,296 \\ & 11,305\end{aligned}$

Stinger

Sections $\left\{\begin{array}{r}11,315 \\ 11,325 \\ 11,335 \\ 11,338\end{array}\right.$

Bottom of

Stinger

(Early in Cooldown)

11,382

Casing Collar 11,400

11,417

11,441

Casing Collar 11,444

11,483

OTIS Packer? 11,485

11,494
$\underline{\Delta L}$

4

4

3

3

4

3

3

3

3

2

2

2

1

2

2

2
Depths on Last Run Out (Full Cooldown)

11,290

11,292

11,302

11,312

11,321

11,332

11,335

11,343

(Full Cooldown)

11,383

11,398

11,415

11,439

11,443

11,481

11,483

11,492 


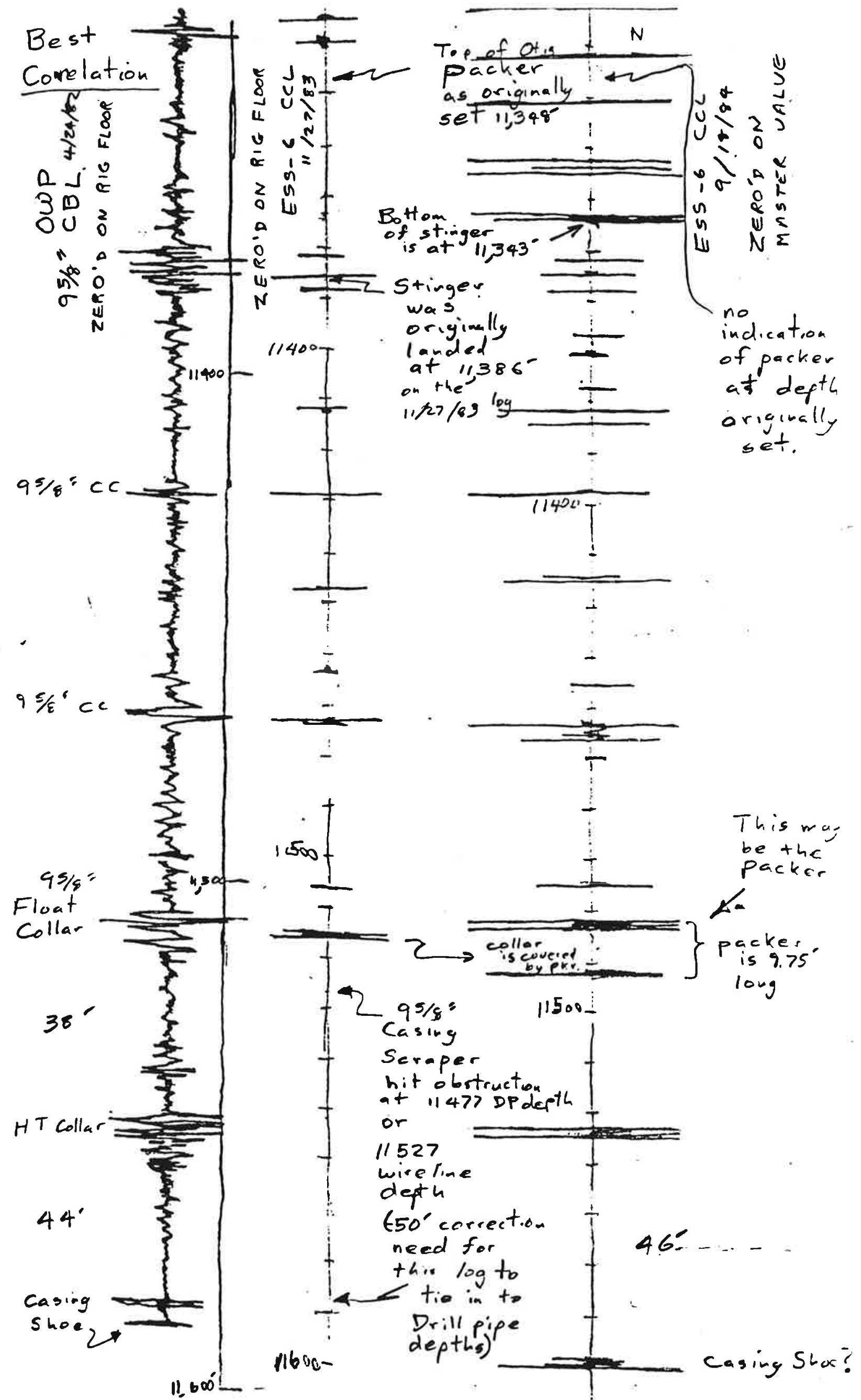




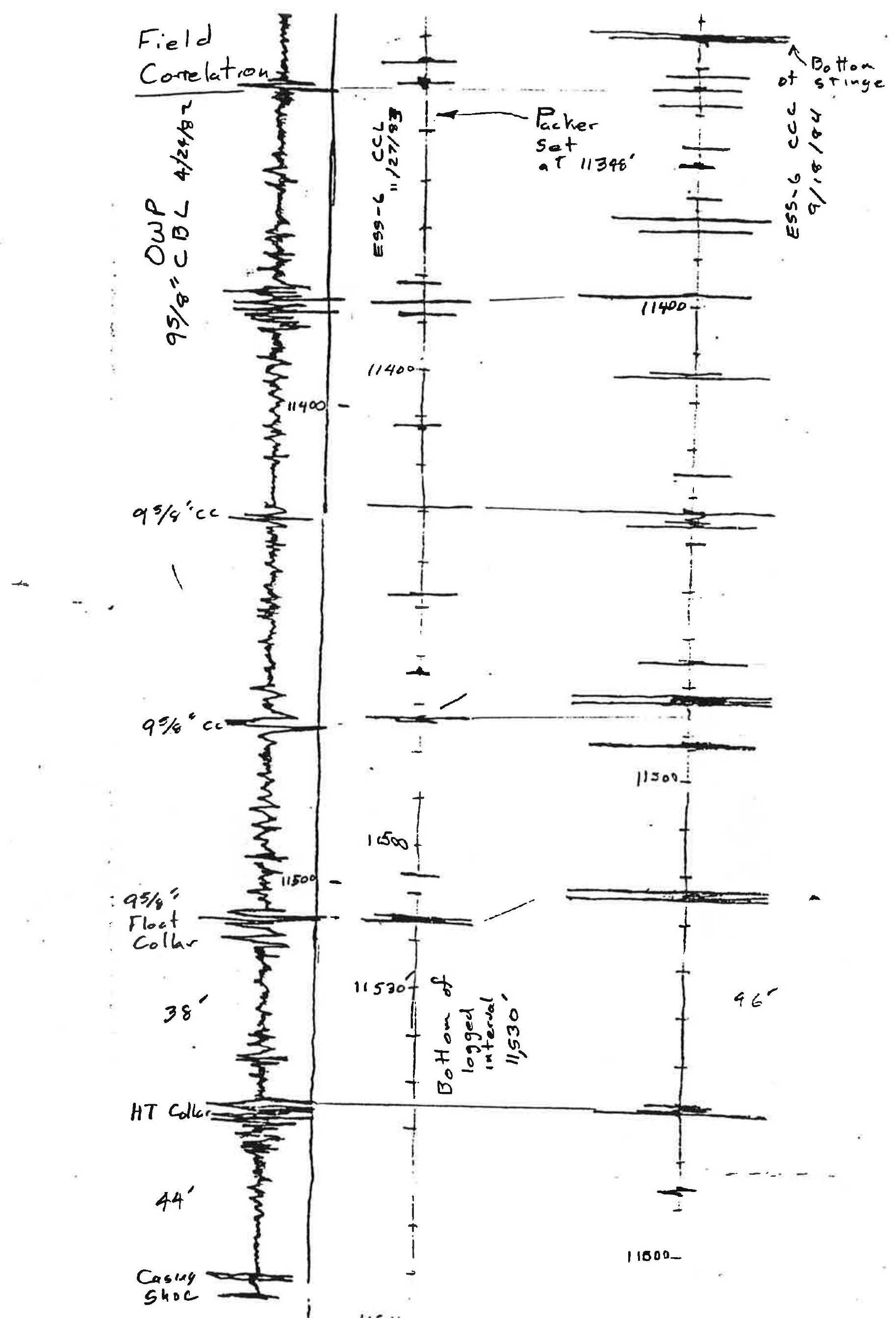




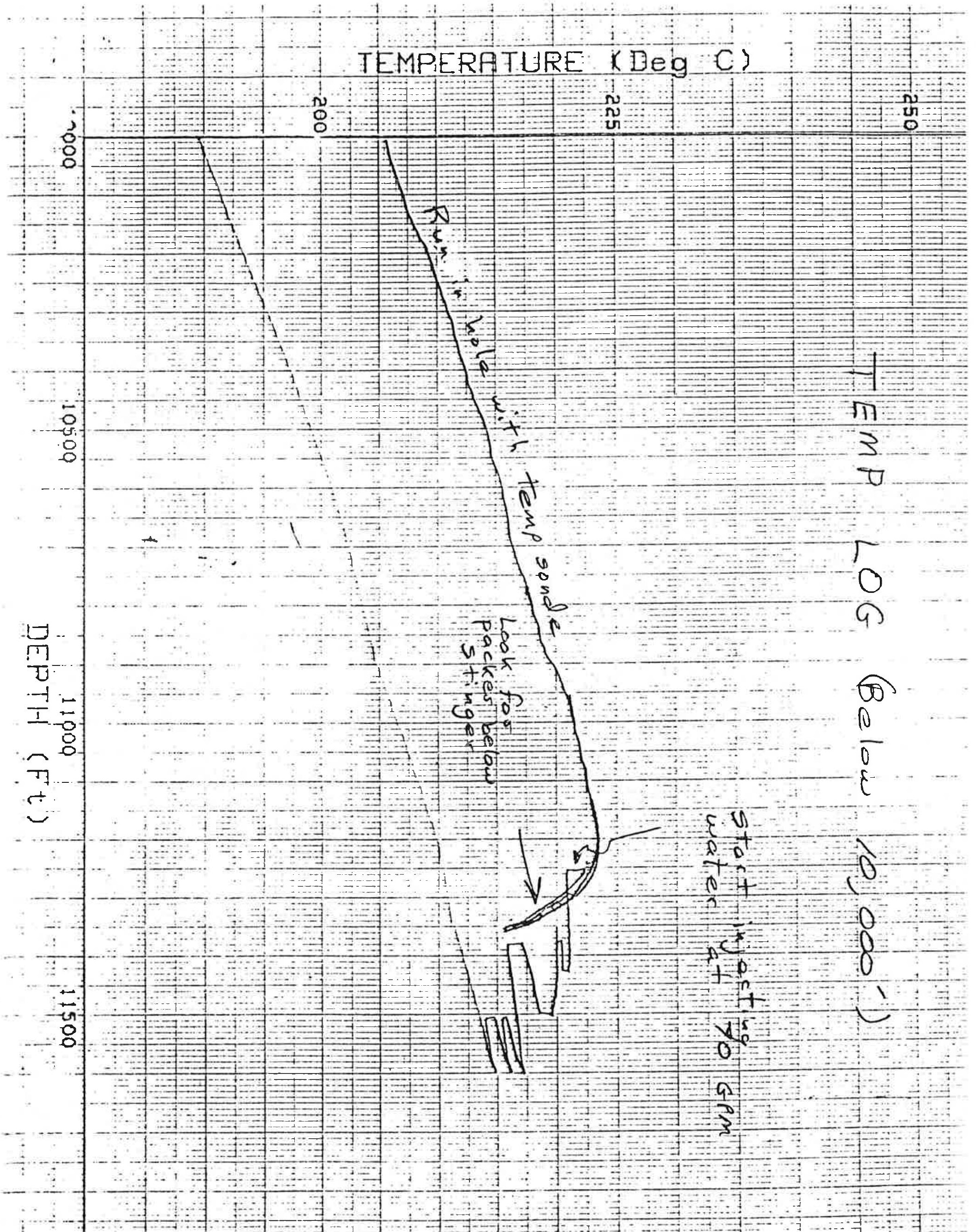




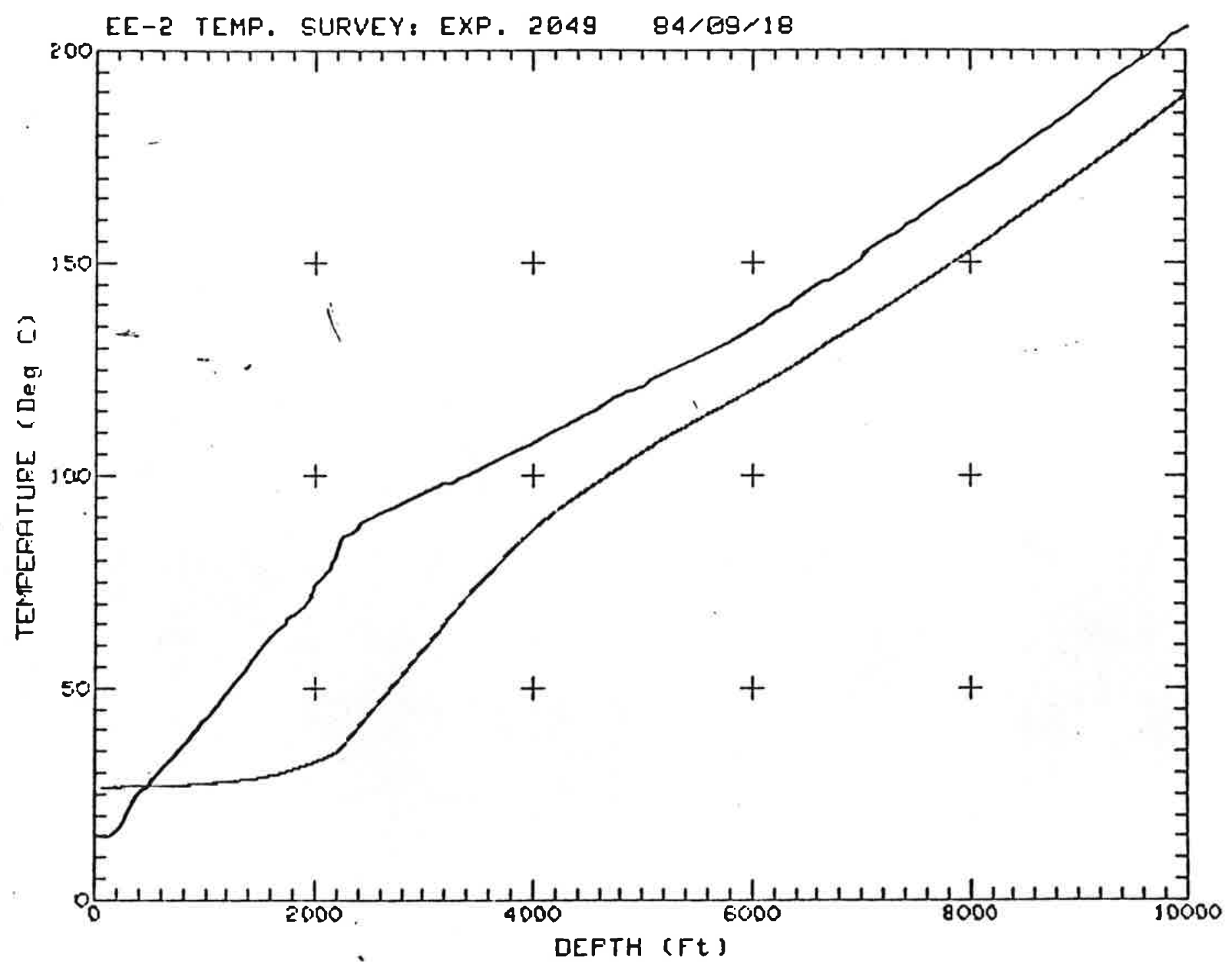

